\title{
HEALTH-PROMOTING BEHAVIORS: PSYCHOMETRIC PROPERTIES OF AN ASSESSMENT TOOL
}

\author{
Catarina Cardoso Tomás ${ }^{1}$, Paulo Joaquim Pina Queirós ${ }^{2}$, Teresa de Jesus Rodrigues Ferreira ${ }^{3}$
}

\footnotetext{
${ }^{1}$ Doctoral student in Nursing Sciences, the Abel Salazar Biomedical Science Institute, Universidade do Porto. Porto, Portugal. E-mail: catarina.tomas@ipleiria.pt

2 Postdoctoral student in Nursing, the Abel Salazar Biomedical Science Institute, Universidade do Porto. Coordinating Professor of the Higher School of Nursing of Coimbra. Coimbra, Portugal. E-mail: pauloqueiros@esenfc.pt

${ }^{3}$ Ph.D. in Psychology. Professor at the Department of Nursing, the Higher School of Nursing of Porto. Porto, Portugal. E-mail: teresarodrigues@esenf.pt
}

\begin{abstract}
Aiming to evaluate the psychometric properties of an instrument to assess the levels of health promoting behaviors, as well as to encounter those same levels related to their age, sex and graduation in a sample of 1213 Portuguese adolescents, the study was conducted of a quantitative, descriptive, correlational, retrospective and cross-sectional. The instrument has good internal consistency (Cronbach's Alpha de 0,889) and reasonable correlations between items (entre $-0,009$ e 0,788), confirming the six factors defined by the authors of the scale. Levels of health-promoting behaviors in the sample are good $(\bar{x}=3,70)$, being higher in girls than boys, and youth to the detriment of younger older. Thus demonstrates the reliability of the instrument in the assessment of healthy behavior in portuguese adolescents, as well as the need for an health intervention in this population.
\end{abstract}

DESCRIPTORS: Health promotion. Adolescent behavior. Validation studies.

\section{COMPORTAMENTOS PROMOTORES DE SAÚDE: PROPRIEDADES PSICOMÉTRICAS DE UM INSTRUMENTO DE AVALIAÇÃO}

RESUMO: Com o objetivo de avaliar as propriedades psicométricas de um instrumento de avaliação dos níveis de comportamentos promotores de saúde, bem como de conhecer esses mesmos níveis numa amostra de 1213 adolescentes portugueses, em relação à sua idade, sexo e ano de escolaridade, foi realizado este estudo, de caráter quantitativo, descritivo-correlacional, retrospetivo e transversal. O instrumento apresenta bons valores de consistência interna (Cronbach's Alpha de 0,889) e razoáveis correlações entre itens (entre $-0,009$ e 0,788 ), confirmando-se os seis fatores definidos pelos autores da escala. Os níveis de comportamentos promotores de saúde na amostra são bons $(\bar{x}=3,70)$, sendo mais elevados nas raparigas do que nos rapazes, e nos jovens mais novos em detrimento dos mais velhos. Demonstra-se assim a fiabilidade do instrumento na avaliação dos comportamentos promotores de saúde nos adolescentes portugueses, e a necessidade de uma intervenção em saúde, nesta população.

DESCRITORES: Promoção da saúde. Comportamento do adolescente. Estudos de validação.

\section{COMPORTAMIENTOS PROMOTORES DE LA SALUD: PROPIEDADES PSICOMÉTRICAS DE UN INSTRUMENTO DE EVALUACIÓN}

\begin{abstract}
RESUMEN: Con el objetivo de evaluar las propiedades psicométricas de un instrumento para evaluar los niveles de comportamientos promotores de la salud, así como para conocerlos en una muestra de 1213 adolescentes portugueses en relación a su edad, sexo y años de escolaridad, se realizó este estudio de tipo cuantitativo, descriptivo, correlacional, retrospetivo y transversal. El instrumento tiene buena consistencia interna (Cronbach's Alpha de 0,889 ) y correlación razonable entre los elementos (entre -0,009 e 0,788), confirmado por los seis factores definidos por los autores de la escala. Los niveles de comportamientos promotores de la salud en la muestra son buenos $(\bar{x}=3,70)$, siendo mayor en las niñas que en los niños, y la juventud en detrimento de los jóvenes mayores. Por lo tanto se demuestra la confiabilidad del instrumento en la evaluación de los comportamientos saludables en los adolescentes portugueses y la necesidad de una intervención de salud en esta población.
\end{abstract}

DESCRIPTORES: Promoción de la salud. Conducta del adolescente. Estudios de validación. 


\section{INTRODUCTION}

Adopting health-promoting behaviors as part of a lifestyle expresses the human tendency towards self-actualization. Above all, such behaviors aim to increase individual well-being and attain personal actualization and accomplishment. ${ }^{1}$ Adopting healthy behaviors and lifestyle involves not only knowledge on the subject, but also the learning and development of emotional, cognitive and behavioral competencies so that such technical and theoretical knowledge can be put to practice in different real life contexts. ${ }^{2}$

Knowledge on healthy lifestyle in adolescence has become an important research topic ${ }^{3}$ and many studies have used the Adolescent Health Promotion Scale (AHPS). Notwithstanding, there is an absence of studies in the Portuguese language or in Portugal.

The authors of this assessment tool used a sample of 1,128 individuals, representative of the Thai adolescent population, and found that the sample presented good levels of health-promoting behaviors (mean of 129 points and median of 130; scores ranged from 51 to 176 points). ${ }^{4}$

On the other hand, a study in Turkey with 1,351 male and female adolescents between the ages of 11 and 19 demonstrated that there were statistically significant differences in terms of gender and age concerning the frequency of healthpromoting behaviors. Adolescent girls presented higher scale mean scores of health-promoting behaviors than boys. Those between the ages of 11 and 14 also presented higher mean scores of health promoting-behaviors than adolescents between 15 and 19. ${ }^{5}$

In China, a study analyzed the level of healthpromoting behaviors among 407 male and female university students between the ages of 16 and 25 (mean age of 21 years), residing both in rural and urban areas. The highest values of health-promoting behaviors were observed for the subscales life appreciation, social support and stress management. Health responsibility and exercise behaviors were the lowest-scoring subscales. Female adolescents presented higher values of health-promoting behaviors (overall scale) than male adolescents, with statistically significant differences, as was also the case of the nutritional behaviors, social support and stress management subscales. However, adolescent boys presented higher values in the exercise behaviors subscale. Adolescents who had been in university for less time presented more favorable results in the life appreciation and exercise behaviors subscales; however, they presented lower scores in the nutritional behaviors subscale in comparison to those who had been at university for a longer period, with statistically significant differences. No relationship was found between health-promoting behaviors and area of residence, whether rural or urban. ${ }^{3}$

Programs aimed at preventing unhealthy lifestyles and risk behaviors are more effective when implemented in early life. ${ }^{4}$ A positive health culture promotes higher levels of health literacy, aiding young people to deal with determinants of health and allowing them to develop the cognitive and social competencies needed for maintaining good health levels. ${ }^{6}$

Health promotion and disease prevention are essential for reducing the need for health care among young people. ${ }^{6}$ International directives give special emphasis to the role of nursing in promoting health and health-promoting behavior. ${ }^{5}$ Nursing, especially school and community nursing, possesses the necessary competencies for promoting the population's health, accessing young people's lifestyles and intervening to facilitate adequate behaviors and reduce inadequate ones. ${ }^{4}$

Considered a science and a professional field, nursing presents a set of concepts and theories integrating a body of knowledge that includes concepts such as health promotion. Such body of knowledge, together with nursing caretaking practices, requires theoretical evidence to sustain its practice. ${ }^{7}$ It is essential that nurses be provided with and trained for new methodological possibilities in the field, as these professionals are currently the social actors responsible for many of the happenings taking place in the health context. ${ }^{8}$

Nola Pender's Health Promotion Model ${ }^{9}$ identifies preceding factors that influence health behaviors. It focuses on eight beliefs that can be assessed by nurses and that are critical points for nursing intervention. In collaboration with patients, nurses can use this model to help clients change behaviors and achieve a healthy lifestyle. Thus, this theory aims to help nursing professionals understand the major determinants of health behaviors as a basis for behavioral counseling to promote healthy lifestyles. This practice is not restricted to explaining disease-preventing behavior, nor does it use fear or threat as a source of motivation. Instead, it focuses on behaviors that can improve health and that are applicable throughout the entire life cycle. ${ }^{9}$ 
The Health Promotion Model provides a classification system that directs research towards predictors of global health, promoting lifestyles and specific behaviors. ${ }^{9}$ The Adolescent Health Promotion Scale was created based on this model. ${ }^{4}$

The main objective of this study was to assess the psychometric properties of the Adolescent Health Promotion Scale ${ }^{4}$ among Portuguese adolescents. In addition to this main objective, we also aimed to assess levels of health-promoting behaviors among adolescents according to gender, age and school year.

The Adolescent Health Promotion Scale consists of 40 Likert items ranging from "never" to "always," and assesses the frequency of certain health-promoting behaviors. Such behaviors are distributed among six subscales, which correspond to several areas of behavior: nutritional behaviors, social support, health responsibility, life appreciation, exercise behaviors and stress management. Answers are scored from 1 to 5 , and the higher the score, the higher the frequency of health promoting behaviors. The authors of the instrument assessed Kaiser-Meyer-Olkin measures (0.942) and Bartlett's sphericity $\left(\chi^{2}=21,609\right.$; $d f=1,128 ; p=0,000)$, which showed that the samples met the criteria for factor analyses. After a Varimax rotation with Kaiser normalization and after deleting factors that were not consistent with the scale, factor analysis yielded six factors with eigenvalues greater than 1.00 and that explained $51.14 \%$ of the variance. Cronbach's Alpha for the total scale was calculated as 0.932 and ranged from 0.748 to 0.878 for the subscales. ${ }^{4}$

\section{METHOD}

The instrument underwent translation and cultural validation for the Portuguese population by using a cross-cultural validation methodology, adapted from the methodology presented by Sousa \& Rojjanasrirat. ${ }^{10}$ This process consisted of the following steps: two independent translations, synthesis I, two independent back-translations, synthesis II, pilot testing, expert panel, and psychometric testing.

Following the translation and cultural validation process, psychometric analysis was included in the form of a descriptive, correlational, retrospective and cross-sectional study of quantitative design.

The study sample comprised adolescents attending high school in the district of Leiria, Por- tugal. Using a non-probabilistic sampling method, we used a convenience sample of 1,213 adolescents. Inclusion criteria consisted of being a high school student at one of the two schools included in the research study in the above-mentioned district. Exclusion criteria were not wanting to participate or minors who did not provide the proper authorization from a parent or legal guardian.

Data were collected with a self-administered questionnaire composed of two parts. The first gathered sociodemographic information and the second consisted of the Adolescent Health Promotion Scale, translated and culturally adapted for the Portuguese population.

This study abided by all formal and ethical research norms and was approved by the ethics committee of the Health Sciences Research Unit - Nursing (resolution no. 57-11/2011), and approved by the General Directorate for Innovation and Curriculum Development of the Portuguese Ministry of Education (registration n. 0241300002).

Psychometric analysis consisted of statistical procedures similar to those employed by the authors of the original study, namely analyzing Cronbach's Alpha and correlation between items (Pearson's correlation test), as well as exploratory factor analysis for the defined subscales. A 5\% chance for a Type I error was allowed for all tests and results obtained.

\section{RESULTS}

The total sample comprised 1,213 participants, of which $640(52.76 \%)$ were male adolescents and $573(47.24 \%)$ were female adolescents. Of the total sample, $34.95 \%(n=424)$ were in their $10^{\text {th }}$ school year, $38.75 \%(n=470)$ in the 11 th year, and $26.30 \%(n=319)$ of participants were in their 12th year. Mean age of participants was 16.32 years ( $\mathrm{s}=1.114)$, and the most prevalent age was 16 $(34.30 \%)$. Sample age varied from 14 to 22 years.

The psychometric properties of the scale met several criteria, including internal consistency, as determined by a Cronbach's Alpha of 0.889 . When any of the items was deleted from the scale, Cronbach's Alpha remained between 0.884 and 0.890 .

Exploratory factor analysis was conducted with six factors (corresponding to the subscales mentioned by the authors of the original scale and whose original structure was maintained). First, the correlation between each of the items that composed each subscale was determined using 
Pearson's correlation test. Resulting values varied between -0.009 (between items 4 and 6 on the nutritional behaviors subscale) and 0.788 (between items 9 and 13 on the social support scale).

The Kaiser-Meyer-Olkin test $(0,887)$ and Bartlett's sphericity test $\left(x^{2}=15420,100 ; \mathrm{df}=780\right.$; $\mathrm{p}=0,000)$ revealed that samples met the criteria for the six-factor exploratory factor analysis, conducted using the main component analysis by Varimax rotation with Keiser normalization (components are described in table 1). Explained total variance was $45,622 \%$ with eigenvalues ranging from 8.231 to 1.528 and components from 0.012 to 0.867 .

The first factor that was obtained corresponded to the life appreciation subscale (items 22 to 29 ), the second factor to stress management (items 35 to 40 ) and the third factor to health responsibility (items 14 to 21). The fourth factor was equivalent to the social support subscale (items 7 to 13), the fifth factor to exercise behaviors (items 30 to 34 ) and the last factor corresponded to nutritional behaviors (items 1 to 6).

Table 1 - Factor analysis through main components analysis following Varimax rotation with Keiser normalization. Leiria, Portugal, 2014

\begin{tabular}{|c|c|c|c|c|c|c|}
\hline Items & $1^{\text {st }}$ factor & $2^{\text {nd }}$ factor & $3^{\text {rd }}$ factor & $4^{\text {th }}$ factor & $5^{\text {th }}$ factor & $6^{\text {th }}$ factor \\
\hline 1 & & & & & & 0.760 \\
\hline 2 & & & & & & 0.152 \\
\hline 3 & & & & & & 0.081 \\
\hline 4 & & & & & & 0.003 \\
\hline 5 & & & & & & 0.270 \\
\hline 6 & & & & & & 0.777 \\
\hline 7 & & & & 0.860 & & \\
\hline 8 & & & & 0.425 & & \\
\hline 9 & & & & 0.864 & & \\
\hline 10 & & & & 0.189 & & \\
\hline 11 & & & & 0.233 & & \\
\hline 12 & & & & 0.225 & & \\
\hline 13 & & & & 0.868 & & \\
\hline 14 & & & 0.603 & & & \\
\hline 15 & & & 0.564 & & & \\
\hline 16 & & & 0.452 & & & \\
\hline 17 & & & 0.303 & & & \\
\hline 18 & & & 0.319 & & & \\
\hline 19 & & & 0.388 & & & \\
\hline 20 & & & 0.597 & & & \\
\hline 21 & & & 0.698 & & & \\
\hline 22 & 0.706 & & & & & \\
\hline 23 & 0.800 & & & & & \\
\hline 24 & 0.177 & & & & & \\
\hline 25 & 0.425 & & & & & \\
\hline 26 & 0.357 & & & & & \\
\hline 27 & 0.527 & & & & & \\
\hline 28 & 0.517 & & & & & \\
\hline 29 & 0.613 & & & & & \\
\hline 30 & & & & & 0.727 & \\
\hline 31 & & & & & 0.780 & \\
\hline 32 & & & & & 0.444 & \\
\hline 33 & & & & & 0.651 & \\
\hline 34 & & & & & 0.250 & \\
\hline 35 & & 0.513 & & & & \\
\hline 36 & & 0.736 & & & & \\
\hline 37 & & 0.643 & & & & \\
\hline
\end{tabular}




\begin{tabular}{ccccccc}
\hline \hline Items & $\mathbf{1}^{\text {st }}$ factor & $\mathbf{2}^{\text {nd }}$ factor & $3^{\text {rd }}$ factor & $4^{\text {th }}$ factor & $5^{\text {th }}$ factor & $\mathbf{6}^{\text {th }}$ factor \\
\hline 38 & & 0.207 & & & & \\
39 & & 0.472 & & & & \\
40 & & 0.470 & & & & \\
Eigenvalue & 8.231 & 3.011 & 2.144 & 1.740 & 1.597 & 1.528 \\
\% of explained variance & 10.086 & 9.323 & 9.140 & 7.133 & 5.688 & 4.252 \\
\hline
\end{tabular}

Cronbach's Alpha was also determined for each factor, presenting values between 0.552 (nutritional behaviors) and 0.843 (life appreciation). Furthermore, values were not significantly altered when some items were deleted from the scale. Thus, Cronbach's Alpha for the subscales and for the total scale were similar.

Following psychometric analysis, the present study assessed the level of health-promoting behaviors presented by the sample of adolescents. The results revealed good levels of health-promoting behaviors, with values above the mean scale value (3), as illustrated in table 2 . The minimum possible score was 40 points and the maximum possible score was 200 . The sample's mean and median scores were both 148, and scores ranged from 86 to 193.

Table 2 - Levels of health-promoting behavior. Leiria, Portugal, 2014

\begin{tabular}{lccccccc}
\hline Subscale & $\overline{\mathbf{x}}$ & $\mathbf{\sigma}$ & Minimum & Maximum & $\mathbf{Q 1}$ & $\mathbf{Q 2}$ & $\mathbf{Q} 3$ \\
\hline Nutritional behaviors & 3.83 & 0.545 & 1.33 & 5.00 & 3.500 & 3.833 & 4.167 \\
Social support & 3.89 & 0.656 & 1.14 & 5.00 & 3.429 & 4.000 & 4.429 \\
Health responsibility & 3.27 & 0.630 & 1.38 & 5.00 & 2.875 & 3.250 & 3.750 \\
Life appreciation & 3.83 & 0.714 & 1.38 & 5.00 & 3.375 & 3.875 & 4.375 \\
Exercise behaviors & 3.82 & 0.714 & 1.00 & 5.00 & 3.400 & 4.000 & 4.400 \\
Stress management & 3.58 & 0.660 & 1.00 & 5.00 & 3.167 & 3.667 & 4.000 \\
\hline Total & $\mathbf{3 . 7 0}$ & $\mathbf{0 . 4 4 4}$ & $\mathbf{2 . 2 3}$ & $\mathbf{4 . 8 3}$ & $\mathbf{3 . 4 1 4}$ & $\mathbf{3 . 7 1 7}$ & $\mathbf{4 . 0 1 8}$ \\
\hline
\end{tabular}

Using a Student's t-test to compare healthpromoting behaviors between genders, very significant statistical differences were found regarding the subscales of social support, health responsibility and exercise behaviors. Adolescent boys presented more frequent exercise behaviors, but girls presented higher levels of social support and health responsibility behaviors, as can be observed in table 3 . Regarding the total scale, no differences were found between genders.

Table 3 - Differences in levels of health-promoting behavior between genders (Student's t-test). Leiria, Portugal, 2014

\begin{tabular}{|c|c|c|c|c|c|c|c|}
\hline Subscale & Gender & $\overline{\mathbf{x}}$ & $\sigma$ & $F$ & $F(\mathrm{p})$ & $t$ & $p^{*}$ \\
\hline \multirow{2}{*}{ Nutritional behaviors } & Male & 3.82 & 0.552 & \multirow{2}{*}{1.139} & \multirow{2}{*}{0.286} & \multirow{2}{*}{-0.951} & \multirow{2}{*}{0.342} \\
\hline & Female & 3.85 & 0.537 & & & & \\
\hline \multirow{2}{*}{ Social support } & Male & 3.80 & 0.686 & \multirow{2}{*}{11.379} & \multirow{2}{*}{0.001} & \multirow{2}{*}{-4.889} & \multirow{2}{*}{$0.000 \dagger$} \\
\hline & Female & 3.98 & 0.607 & & & & \\
\hline \multirow{2}{*}{ Health responsibility } & Male & 3.18 & 0.643 & \multirow{2}{*}{3.197} & \multirow{2}{*}{0.074} & \multirow{2}{*}{-5.695} & \multirow{2}{*}{$0.000 \dagger$} \\
\hline & Female & 3.38 & 0.597 & & & & \\
\hline \multirow{2}{*}{ Life appreciation } & Male & 3.83 & 0.766 & \multirow{2}{*}{19.462} & \multirow{2}{*}{0.000} & \multirow{2}{*}{-0.158} & \multirow{2}{*}{0.874} \\
\hline & Female & 3.83 & 0.650 & & & & \\
\hline \multirow{2}{*}{ Exercise behaviors } & Male & 3.91 & 0.741 & \multirow{2}{*}{7.438} & \multirow{2}{*}{0.006} & \multirow{2}{*}{4.961} & \multirow{2}{*}{$0.000 \dagger$} \\
\hline & Female & 3.71 & 0.666 & & & & \\
\hline \multirow{2}{*}{ Stress management } & Male & 3.56 & 0.673 & \multirow{2}{*}{0.804} & \multirow{2}{*}{0.370} & \multirow{2}{*}{-0.846} & \multirow{2}{*}{0.397} \\
\hline & Female & 3.59 & 0.644 & & & & \\
\hline \multirow{2}{*}{ Total } & Male & 3.68 & 0.473 & \multirow{2}{*}{14.077} & \multirow{2}{*}{0.000} & \multirow{2}{*}{-1.641} & \multirow{2}{*}{0.101} \\
\hline & Female & 3.72 & 0.408 & & & & \\
\hline
\end{tabular}

${ }^{*} p \leq 0.05 ; \uparrow p \leq 0.01$. 
Differences among adolescents in different school years concerning health-promoting behaviors were analyzed with one-way ANOVA. Statistically significant differences were found between groups with respect to nutritional healthpromoting behaviors $(p=0.016)$, and very statistically significant differences regarding exercise behaviors $(p=0.000)$, stress management $(p=0.002)$, and total score $(\mathrm{p}=0.006)$.
To determine which school years presented statistically significant differences between them, Tukey's post-hoc test was applied, as demonstrated in table 4 . Adolescents in the $10^{\text {th }}$ school year presented higher levels of health-promoting behaviors in all the subscales that presented statistically significant differences, in addition to total healthpromoting behaviors. Adolescents in the $11^{\text {th }}$ year presented the lowest values for these behaviors.

Table 4 - Differences in levels of health-promoting behaviors according to nutritional behaviors, exercise behaviors and stress management, and total behaviors among adolescents in different school years (Tukey's test). Leiria, Portugal, 2014

\begin{tabular}{ccccccccc}
\hline Subscale & $\mathbf{a})$ & $\mathbf{b})$ & $\overline{\mathbf{x}} \mathbf{a})$ & $\boldsymbol{\sigma} \mathbf{a})$ & $\overline{\mathbf{x}} \mathbf{b})$ & $\boldsymbol{\sigma} \mathbf{b})$ & Difference of $\overline{\mathbf{x}}(\mathbf{a}-\mathbf{b})$ & $p$ \\
\hline \multirow{3}{*}{ Nutritional behaviors } & $10^{\text {th }}$ year & $11^{\text {th }}$ year & 3.88 & 0.531 & 3.78 & 0.543 & 0.102 & $0.014^{*}$ \\
& $10^{\text {th }}$ year & $12^{\text {th }}$ year & 3.88 & 0.531 & 3.85 & 0.560 & 0.032 & 0.706 \\
& $11^{\text {th }}$ year & $12^{\text {th }}$ year & 3.78 & 0.543 & 3.85 & 0.560 & -0.070 & 0.175 \\
\hline \multirow{3}{*}{ Exercise behaviors } & $10^{\text {th }}$ year & $11^{\text {th }}$ year & 3.92 & 0.705 & 3.74 & 0.700 & 0.186 & $0.000 \dagger$ \\
& $10^{\text {th }}$ year & $12^{\text {th }}$ year & 3.92 & 0.705 & 3.78 & 0.729 & 0.146 & $0.016^{*}$ \\
& $11^{\text {th }}$ year & $12^{\text {th }}$ year & 3.74 & 0.700 & 3.78 & 0.729 & -0.040 & 0.719 \\
\hline \multirow{3}{*}{ Stress management } & $10^{\text {th }}$ year & $11^{\text {th }}$ year & 3.64 & 0.675 & 3.50 & 3.627 & 0.146 & $0.003 \dagger$ \\
& $10^{\text {th }}$ year & $12^{\text {th }}$ year & 3.64 & 0.675 & 3.61 & 0.674 & 0.032 & 0.784 \\
& $11^{\text {th }}$ year & $12^{\text {th }}$ year & 3.50 & 3.627 & 3.61 & 0.674 & -0.114 & $0.046^{*}$ \\
\hline \multirow{6}{*}{ Total } & $\mathbf{1 0}^{\text {th }}$ year & $\mathbf{1 1}^{\text {th }}$ year & 3.75 & $\mathbf{0 . 4 4 1}$ & 3.66 & $\mathbf{0 . 4 4 0}$ & $\mathbf{0 . 0 9 7}$ & $\mathbf{0 . 0 0 4 \dagger}$ \\
& $\mathbf{1}^{\text {th }}$ year & $\mathbf{1 2}^{\text {th }}$ year & 3.75 & $\mathbf{0 . 4 4 1}$ & 3.71 & $\mathbf{0 . 4 4 8}$ & $\mathbf{0 . 0 4 8}$ & $\mathbf{0 . 3 1 4}$ \\
& $\mathbf{1 1}^{\text {th }}$ year & $\mathbf{1 2}^{\text {th }}$ year & 3.66 & $\mathbf{0 . 4 4 0}$ & 3.71 & $\mathbf{0 . 4 4 8}$ & $\mathbf{- 0 . 0 4 9}$ & $\mathbf{0 . 2 9 6}$ \\
\hline
\end{tabular}

${ }^{*} p \leq 0.05 ; \uparrow p \leq 0.01$.

Pearson's test was conducted to test the correlation between levels of health-promoting behaviors and the age of participants and presented significant results as described in table 5 . Statistically significant correlations were found between age and health-promoting behaviors in the social support subscale. Very significant correlations were observed between age and nutritional behaviors, exercise behaviors and total behaviors, being that the older the adolescent, the less frequent the behaviors.

Table 5 - Correlation between levels of healthpromoting behaviors and age of the adolescents (Pearson's correlation test). Leiria, Portugal, 2014

\begin{tabular}{|c|c|c|c|c|}
\hline & Subscale & $R$ & $R^{2}$ & $p$ \\
\hline \multirow{7}{*}{ Age } & Nutritional behavior & -0.077 & -0.047 & $0.007 \dagger$ \\
\hline & Social support & -0.056 & -0.041 & $0.050^{*}$ \\
\hline & Health responsibility & -0.026 & -0.018 & 0.373 \\
\hline & Life appreciation & -0.033 & -0.026 & 0.250 \\
\hline & Exercise behaviors & -0.155 & -0.123 & $0.000 \dagger$ \\
\hline & Stress management & -0.037 & -0.027 & 0.198 \\
\hline & Total & -0.095 & -0.047 & $0.001 \dagger$ \\
\hline
\end{tabular}

Text Context Nursing, Florianópolis, 2015 Jan-Mar; 24(1): 22-9.

\section{DISCUSSION}

The Portuguese version of the Adolescent Health Promotion Scale presented good internal consistency and item validity for evaluating levels of health-promoting behaviors among Portuguese adolescents.

Internal consistency values remained constant when any item was deleted from the scale, thus none were dispensable even though correlations were weaker. Cronbach's alpha was slightly lower than those obtained by the authors of the original instrument; notwithstanding, they still classified as good. ${ }^{4}$ Furthermore, the percentage of explained variance was not as high (although the difference was not very accentuated) as the original scale, even though the factor analysis applied in this study was exactly the same as that used by its authors. ${ }^{4}$

Although such differences between the results of this study and those of the original scale were not significant, they can be explained by sampling differences. Thus, further studies with this instrument are needed to confirm the present findings. However, the validity of the instrument with six 
defined subscales has been demonstrated, according to the theoretical model set forth by its authors. ${ }^{4}$

Regarding total health-promoting behaviors, the mean score of this study sample was 19 points higher than that of the original authors. In both cases, such levels were considered good. ${ }^{4}$ The subscale with the highest scores of levels of healthpromoting behaviors was social support, followed by life appreciation and nutritional behaviors. The lowest-scoring subscale was health responsibility, followed by stress management.

The authors of the Chinese study mentioned above found results similar to those of the present study in terms of levels of health-promoting behaviors. However, the stress management subscale presented higher levels than in the present study and the exercise behaviors subscale presented lower levels. ${ }^{3}$

These data suggest that the adolescents in this study do present more health-promoting exercise behaviors. However, they would benefit from learning more effective stress management strategies in order to increase scores in this subscale.

Regarding the participants' gender, higher values of health-promoting behaviors were found among female adolescents in the social support and health responsibility subscales. On the other hand, male adolescents presented higher levels of health-promoting exercise behaviors. ${ }^{3}$ Levels of health-promoting behaviors were higher in female than male participants, but they were not statistically significant, contrary to other studies that found much more accentuated differences. ${ }^{3,5}$ Such differences between genders demonstrate the need for distinct interventions focused on the lowest-scoring health-promoting behaviors for each group.

Considering the participants' age and school year, levels of health-promoting behaviors were higher among younger adolescents ${ }^{5}$ and those in more advanced grades, namely between age and total behaviors, nutritional behaviors, social support and exercise behaviors, and between school year and nutritional behaviors, exercise behaviors, stress management and total behaviors. Nonetheless, other studies with similar results found that health-promoting nutritional behaviors were more common among older adolescents. ${ }^{3}$ Thus, the older the adolescent, the lower the level of healthpromoting behaviors. This finding highlights the risk of adolescents transitioning to adult age with poorer health and, above all, displaying unhealthy habits that can reflect in future poor health.
These results reflect the need for the field of nursing to invest in health education, promote health literacy and aid in the development of competencies of this specific age group in order to modify this reality.

\section{FINAL CONSIDERATIONS}

The Portuguese version of the Adolescent Health Promotion Scale presented good psychometric indicators, indicating its viability for assessing health-promoting behaviors and reliably assessing this concept among the Portuguese adolescent population. The instrument maintained the initial theoretical subscales defined by its authors, assessing health-promoting behaviors with regards to six areas. Generalizability of results could be obtained if the instrument were to be applied in other studies and different contexts. It did not occur in the present study given the selected mode of sample selection. Moreover, replicating the study would certify the instrument's viability and sensitivity in assessing the concept of healthpromoting behaviors among the Portuguese adolescent population.

Levels of health-promoting behaviors were considered good and statistically significant differences were found between genders. The participants' age was inversely correlated with the level of health-promoting behaviors, i.e., such behaviors decreased as the participants' age increased. Furthermore, the further along in their studies, the lower the levels of health-promoting behaviors presented by students, corroborating the correlation found between such levels and adolescent age.

International guidelines emphasize the importance of nurses' role in health promotion and adolescents are a group of special interest for such interventions. Work with this age group can promote a more effective development of cognitive and social competencies that are required for maintaining good health levels during adolescence and posterior life phases. Nursing professionals, especially those working with school and community health, possess the competencies that are essential to promoting social, personal and cognitive skills in youth. In addition, they are able to assess and focus on the need for more specific interventions within each group of adolescents with the objective of promoting a healthy transition to adult life. The results obtained in this research can provide professionals with a form of assessment and help direct and base their work on the specific needs of adolescents. 


\section{REFERENCES}

1. Chang LC. Health Literacy, self-reported status and health promoting behaviours for adolescents in Taiwan. J Clin Nurs. 2010 Jan; 20(1-2):190-6.

2. Santos O. O papel da literacia em saúde: capacitando a pessoa com excesso de peso para o controlo e redução da carga ponderal. Rev ENDO. 2010 Jul; $3(4): 127-34$.

3. Wang D, Ou CQ, Chen MY, Duan N. Health promoting lifestyles of university students in Mainland China. BMC Public Health. 2009 Oct 9;9:379.

4. Chen MY, Wang E, Yang RJ, Liou YM. Adolescent Health Promotion Scale: Development and Psychometric Testing. Public Health Nurs. 2003 Mar-Abr; 20(2):104-10.

5. Ortabag T, Ozdemir S, Bakir B, Tosun N. Health Promotion and Risk Behaviors Among Adolescents in Turkey. J Sch Nurs. 2011 Ago; 27(4):304-15.
6. Lee A. Health promoting schools: evidence for a holistic approach to promoting health and improving health literacy. Appl Health Econ Health Policy. 2009; 7(1):11-7.

7. Lopes M, Saraiva KR, Fernandes AF, Ximenes LB. Análise do conceito de Promoção da Saúde. Texto Contexto Enferm. 2010 Jul-Set; 19(3):461-8.

8. Salci MA, Maceno P, Rozza SG, Silva DM, Boehs AE, Heidemann IT. Educação em Saúde e suas perspectivas teóricas: Algumas reflexões. Texto Contexto Enferm. [online] 2013 Jan-Mar [acesso 2014 Out 07]; 22(1): 224-30. Disponível em: http:/ / dx.doi. org/10.1590/S0104-07072013000100027.

9. Pender NJ, Parsons M A, Murdaugh C. Health promotion in nursing practice. $6^{\mathrm{a}}$ ed. Boston (US): Pearson; 2010.

10. Sousa VD, Rojjanasrirat W. Translation, adaptation and validation of instruments or scales for use in crosscultural health care research: a clear and user-friendly guideline. J Eval Clin Pract. 2010 Abr; 17(2): 268-74. 